\title{
Characteristics of Kitchen Waste and the Formation of Floating Brown Particles (FBP) in the Anaerobic Digestion Process
}

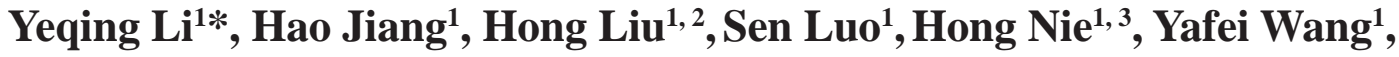 \\ Mingyu Qian ${ }^{1,4}$, Jiangtao Ding ${ }^{1}$, Hongjun Zhou ${ }^{1 * *}$ \\ ${ }^{1}$ Institute of New Energy, State Key Laboratory of Heavy Oil Processing, Beijing Key Laboratory of Biogas Upgrading \\ Utilization, China University of Petroleum Beijing (CUPB), Beijing, P. R. China, 102249 \\ ${ }^{2}$ Beijing Jeegreen Technology Development Co., Ltd., Beijing, P. R. China, 102200 \\ ${ }^{3}$ Institute of Agricultural Applied Microbiology, Jiangxi Academy of Agricultural Sciences, \\ Nanchang, P. R. China, 330200 \\ ${ }^{4}$ Faculty of Agricultural and Environmental Sciences, University of Rostock, \\ Justus-von-Liebig-Weg 6, 18059 Rostock, Germany
}

Received: 14 March 2017

Accepted: 15 June 2017

\begin{abstract}
Five types of kitchen waste (KW) from China - including hop pot (HP), fast food (FF), Hebei cuisine (HC), university canteen (UC), and other mixed KW (Other) - were investigated as feedstock for potential biogas and methane production. The biodegradability of KW was measured using batch anaerobic digestion (AD) tests and feedstock at an inoculum ratio (F/I) of 0.5. Gompertz and Cone models were used to determine the kinetic parameters of KW degradation, biogas, and methane production. Results showed that HP had the highest lag phase time of 5.46 days. Methane production varies with different sources of KW. HP had the highest methane yield of $363.9 \mathrm{~mL} / \mathrm{g}-\mathrm{VS}_{\text {added }}$ as compared to a sample of FF (334.8 mL/g-VS added $_{1}$ ), other (278.5 mL/g-VS added $)$ UC (239.2 mL/g-VS added $)$, and HC (236.0 mL/g-VS added $)$. The biodegradability of KW ranged from $39.5 \%$ to $50.4 \%$. During the AD process a certain amount of floating brown particles (FBP) were formed, which may be the main inhibiting factor of methane production. Analysis of ${ }^{13} \mathrm{C}$ NMR and FTIR revealed that the main component of FBP was calcium stearate. The formation mechanism of calcium stearate may contribute to the relatively high lipid content (18.6\% to $30.9 \%)$ of the KW sample, which subsequently resulted in over-accumulation of long-chain fatty acids (LCFAs) and reaction with $\mathrm{Ca}^{2+}$. Using lipid-rich substrates as feedstock may be an efficient approach to adding $\mathrm{Ca}^{2+}$ artificially for reducing the inhibition of LCFAs.
\end{abstract}

Keywords: kitchen waste, biodegradability, floating brown particles, anaerobic digestion, calcium stearate

Yeqing Li and Hao Jiang contributed to this work equally.

Yeqing $\mathrm{Li}$ and Hongjun Zhou were the corresponding authors.

*e-mail: liyeqing@cup.edu.cn

**e-mail: zhhj63@163.com 


\section{Introduction}

With the growth of population and development of the worldwide economy, kitchen waste (KW), including uneaten food and food leftovers from restaurants, households, canteens, and companies, is increasingly produced. As the world's most populous country, China produces approximate 90 million tons of KW each year [1]. Beijing, the second largest Chinese city by urban area, produces 1,700 tons of KW daily [2]. The uncontrolled discharge of large amounts of KW causes severe environmental problems such as land pollution, odors, and greenhouse gases emissions [3].

Traditional approaches for KW disposal are mainly landfills, incineration, and aerobic composting. In term of eco-friendly and cost-effective measures, anaerobic digestion (AD) is a promising method that has been increasingly studied. Additionally, KW has high moisture content of $74-90 \%$, which is more adaptable for $\mathrm{AD}$ compared to conventional technologies. In the AD process, organics are gradually hydrolyzed to small molecular materials and soluble organic substrates (e.g., acetate), which could be used by methanogens for methane production.

Due to complex constituents in Chinese KW, the biogas production performance varies with different sources of KW [4]. Lipid-rich waste contributes a considerable amount to the total quantity of KW. Theoretically, the methane potential of lipids is $1,014 \mathrm{~L} / \mathrm{kg}-\mathrm{VS}_{\text {added }}$, a value higher than of carbohydrates and protein (e.g., $415 \mathrm{~L} / \mathrm{kg}-$ $\mathrm{VS}_{\text {added }}$ for glucose and $496 \mathrm{~L} / \mathrm{kg}-\mathrm{VS}_{\text {added }}$ for protein) [5]. The actual methane production, however, is unsatisfactory due to the inhibition of main intermediate by-products (e.g., long-chain fatty acids or LCFAs) derived from the lipid degradation process as well as mass transfer problems for soluble substrates as they become adsorbed to the microbial biomass surface [6]. Later studies demonstrated that samples with higher lipid content produced more methane with relative extensions of initial lag phase time [7]. In the current work, the phenomenon of "floating brown particles" (FBP) appeared during AD of KW. To find the composition of FBP, an energy dispersive $\mathrm{X}$-ray analyzer, ${ }^{13} \mathrm{C}$ nuclear magnetic resonance (NMR), and a Fourier transform infrared spectrometer (FTIR) were used. The main objectives of this study were: 1) to investigate the effect of different KW sources on biogas and methane production performance and 2) to find the composition and formation mechanism of FBPs.

\section{Methods}

\section{Feedstock and Inoculum}

Five kinds of kitchen waste (KW) were sampled from different places (Table 1). Each kind of KW was obtained from mixing two or three different samples collected from the same type of place. Once collected, KW was shredded into particles with an average size of $3.0 \mathrm{~mm}$ and
Table 1. Kitchen waste and sample sources.

\begin{tabular}{|c|c|c|}
\hline KW sample & Sample source & Replication (n) \\
\hline HC & Hebei cuisine restaurants & $\mathrm{n}=4$ \\
\hline FF & Fast food & $\mathrm{n}=4$ \\
\hline HP & Hot pot & $\mathrm{n}=6$ \\
\hline UC & University canteens & $\mathrm{n}=4$ \\
\hline Other & $\begin{array}{c}\text { Barbecue, buffet, canteens, } \\
\text { Shandong and Yunnan cuisines }\end{array}$ & $\mathrm{n}=6$ \\
\hline
\end{tabular}

kept at $-18^{\circ} \mathrm{C}$ for later use. Digested sludge from a stable operated CSTR reactor of Asuwei Landfill (Changping District, Beijing, China) was selected as inoculum. Prior to inoculation, inoculum was acclimated (pre-incubation) for two weeks in a constant temperature incubator shaker (ZWYR-D2402, China) by adding mixed KW at $42 \pm 1^{\circ} \mathrm{C}$ [8-9]. Unpublished data from biogas plant surveys suggest that average temperatures of mesophilic $\left(35-45^{\circ} \mathrm{C}\right)$ digesters of full-scale biogas plants was $40^{\circ} \mathrm{C}$, therefore the performance of trials at $42^{\circ} \mathrm{C}$ seems legitimate to us. After acclimatization, the total solids (TS), volatile solids (VS), and $\mathrm{pH}$ of inoculum was determined to be $2.02 \%$, $0.88 \%$, and 7.17 , respectively. As previous research suggested that thermo-pretreatment could reduce the content of oil and accelerate the hydrolysis of KW [10], KW used in this study was treated by a high-temperature sterilization pot (Panasonic MLS-3751L) at $120^{\circ} \mathrm{C}$ for two hours. Processed samples were then kept at $4^{\circ} \mathrm{C}$ before use.

\section{Batch Experiments}

Biochemical methane potential (BMP) tests were conducted in batch mode using glass bottles with a total volume of $250 \mathrm{~mL}$ and a working volume of $200 \mathrm{~mL}$. The initial VS concentration of KW was $6.67 \mathrm{~g}-\mathrm{VS} / \mathrm{L}$ and the corresponding feedstock-to-inoculum (F/I) ratio was adjusted to 0.5 (on VS basis) [11]. After the addition of inoculum and substrates, tap water was added to digesters to make a final working volume of $200 \mathrm{~mL}$. To ensure an oxygen-free environment, nitrogen was continuously passed though the loaded glass bottles for two minutes. Digesters were then placed in a constant temperature incubator shaker (ZWYR-D2402, China) for three weeks. The digestion temperature was $42 \pm 1^{\circ} \mathrm{C}$ and shaking rate was $100 \mathrm{rpm}$. Control samples were set up by adding the same amount of inoculum and water instead of KW.

\section{Analytical Methods}

TS and VS were determined according to standard methods [12]. Major elements of organic of the KW samples (such as $\mathrm{C}, \mathrm{H}, \mathrm{N}$, and S) were measured by an elemental analyzer (EA3000, Italy). The contents of $\mathrm{Fe}, \mathrm{Cu}, \mathrm{Mn}, \mathrm{Zn}$, $\mathrm{Ca}$, and $\mathrm{Mg}$ of the KW samples were analyzed by means of x-ray fluorescence (Panalytical, Petro-Axiosm AX, 
Holland). Cellulose, hemicellulose, and lignin were tested by an ANKOM fiber analyzer (A200, America). Crude fat was measured according to the Soxhlet extraction method with a crude fat determination instrument (SZF06G, China). Crude protein was determined by a Kjeldahl nitrogen instrument (KDY-9820, China).

Biogas production was measured once per day using an ANKOM RFS gas production system. Biogas composition was analyzed once per day using a gas chromatograph (FULI 9790II, China) equipped with a thermal conductivity detector and helium as the carrier gas. The temperatures of the injector, oven, and detector were 150,130 , and $160^{\circ} \mathrm{C}$, respectively.

After digestion, floating brown particles (FBP) were formed in all digesters. To investigate the composition of FBP, an energy-dispersive x-ray analyzer (EX-350, HORIBA EMAX Energy, Japan) was used under the test conditions of $15 \mathrm{kV}$. The images were taken using a scanning electron microscope (SEM) at 10,000 and 30,000 magnification. The functional groups of FBP were analyzed using an FTIR spectrometer (Bruker vertex 70v, Germany). The solid samples were mixed with $\mathrm{KBr}$, ground to a fine powder, and pressed into pellets for infrared (IR) transmission studies. Spectral information was collected over a wave number range from 4000 to $400 \mathrm{~cm}^{-1}$. Furthermore, the functional groups of FBP were analyzed by ${ }^{13} \mathrm{C}$ nuclear magnetic resonance (NMR).

\section{Kinetic Models}

First-order reaction constant $(k)$ is a vital parameter for predicting the feasibility of using feedstocks for largescale biogas production. Besides, the lag phase time $(\lambda)$ is also important for designing an AD plant. In this study, modified Gompertz (Eq. (1)) and Cone (Eq. (2)) models were used to determine the $k$ and $\lambda$ values [13].

$$
\begin{gathered}
B=B_{0} \exp \left\{-\exp \left[\frac{\mu_{m} e}{B_{0}}(\lambda-t)+1\right]\right\} \\
B=\frac{0}{1+(k t)^{-n}}
\end{gathered}
$$

\begin{tabular}{|c|c|c|c|c|c|c|c|c|}
\hline \multicolumn{6}{|c|}{ This study } & \multirow{2}{*}{ [4] } & \multirow{2}{*}{ [16] } & \multirow{2}{*}{ [17] } \\
\hline Parameters & HP & $\mathrm{HC}$ & $\mathrm{FF}$ & UC & Other & & & \\
\hline TS, \%* & $14.56 \pm 1.14$ & $19.35 \pm 1.29$ & $20.02 \pm 2.22$ & $16.85 \pm 2.86$ & $23.37 \pm 1.60$ & $30.90 \pm 0.07$ & $23.1 \pm 0.3$ & $18.9 \pm 2.3$ \\
\hline VS, \%* & $13.09 \pm 1.17$ & $18.03 \pm 1.71$ & $18.72 \pm 2.23$ & $15.31 \pm 3.09$ & $21.45 \pm 1.37$ & $26.35 \pm 0.14$ & $21.0 \pm 0.3$ & $17.5 \pm 1.8$ \\
\hline VS/TS, \%* & $89.84 \pm 1.28$ & $93.13 \pm 2.65$ & $93.50 \pm 0.75$ & $90.59 \pm 2.95$ & $91.80 \pm 1.12$ & $85.30 \pm 0.65$ & $90.9 \pm 0.2$ & $93.0 \pm 2.0$ \\
\hline C, \%TS & $55.80 \pm 3.83$ & $52.31 \pm 0.08$ & $53.03 \pm 5.92$ & $49.95 \pm 5.55$ & $56.98 \pm 1.86$ & $46.78 \pm 1.15$ & $56.3 \pm 1.1$ & $53.3 \pm 1.2$ \\
\hline N, \%TS & $2.71 \pm 0.10$ & $2.74 \pm 0.40$ & $1.99 \pm 0.02$ & $2.87 \pm 0.11$ & $3.48 \pm 0.10$ & $3.16 \pm 0.22$ & $2.3 \pm 0.3$ & $2.5 \pm 0.2$ \\
\hline $\mathrm{C} / \mathrm{N}, \%$ & $20.59 \pm 1.74$ & $19.33 \pm 2.82$ & $26.69 \pm 2.71$ & $17.46 \pm 2.62$ & $16.39 \pm 1.00$ & 14.8 & $24.5 \pm 1.1$ & 21.3 \\
\hline H, \%TS & $8.35 \pm 0.43$ & $7.98 \pm 0.02$ & $8.25 \pm 0.97$ & $7.60 \pm 0.99$ & $8.10 \pm 0.84$ & NG & NG & NG \\
\hline $\mathrm{O}^{\mathrm{a}}, \% \mathrm{TS}$ & $23.90 \pm 4.17$ & $28.80 \pm 1.23$ & $30.23 \pm 5.81$ & $30.87 \pm 4.85$ & $24.61 \pm 2.97$ & NG & NG & NG \\
\hline S, \%TS & $0.31 \pm 0.39$ & $0.10 \pm 0.04$ & $0.08 \pm 0.02$ & $0.30 \pm 0.14$ & $0.18 \pm 0.07$ & $0.25 \pm 0.01^{\mathrm{b}}$ & NG & $0.27 \pm 0.01^{\mathrm{b}}$ \\
\hline $\mathrm{Cl}, \% \mathrm{TS}$ & $7.39 \pm 0.72$ & $7.10 \pm 0.13$ & $8.03 \pm 2.97$ & $8.11 \pm 3.40$ & $6.60 \pm 0.89$ & NG & NG & NG \\
\hline P, \%TS & $0.68 \pm 0.13$ & $0.66 \pm 0.16$ & $0.84 \pm 0.69$ & $0.39 \pm 0.05$ & $0.75 \pm 0.17$ & $0.52 \pm 0.08$ & NG & $0.19 \pm 0.00$ \\
\hline $\mathrm{K}, \% \mathrm{TS}$ & $2.82 \pm 0.14$ & $2.65 \pm 0.53$ & $2.22 \pm 0.72$ & $1.82 \pm 0.28$ & $2.14 \pm 0.33$ & $0.90 \pm 0.11$ & $2.30 \pm 0.04$ & $0.01 \pm 0.00$ \\
\hline Ca, \%TS & $3.94 \pm 0.94$ & $3.75 \pm 1.69$ & $2.74 \pm 1.05$ & $3.18 \pm 0.17$ & $3.83 \pm 0.50$ & $2.16 \pm 0.29$ & $0.40 \pm 0.01$ & $<0.01$ \\
\hline Na, \%TS & $2.98 \pm 0.09$ & $2.97 \pm 0.03$ & $3.49 \pm 2.53$ & $3.31 \pm 2.09$ & $2.23 \pm 0.69$ & NG & $3.45 \pm 0.20$ & $0.19 \pm 0.00$ \\
\hline Mg, \%TS & $0.18 \pm 0.02$ & $0.16 \pm 0.01$ & $0.18 \pm 0.13$ & $0.12 \pm 0.04$ & $0.12 \pm 0.03$ & $0.14 \pm 0.01$ & $0.16 \pm 0.01$ & $<0.01$ \\
\hline $\mathrm{Al}, \% \mathrm{TS}$ & $0.03 \pm 0.01$ & $0.02 \pm 0.01$ & $0.04 \pm 0.01$ & $0.04 \pm 0.02$ & $0.02 \pm 0.01$ & $0.12 \pm 0.04^{b}$ & NG & $<0.01$ \\
\hline Zn, \%TS & $0.02 \pm 0.00$ & $0.02 \pm 0.00$ & $0.02 \pm 0.00$ & $0.01 \pm 0.00$ & $0.02 \pm 0.00$ & $0.01 \pm 0.00^{\mathrm{b}}$ & $0.02 \pm 0.00^{b}$ & $<0.01$ \\
\hline $\mathrm{Cu}, \% \mathrm{TS}$ & $0.02 \pm 0.01$ & $0.01 \pm 0.00$ & $0.01 \pm 0.01$ & 0 & $0.01 \pm 0.00$ & $<0.01^{\mathrm{b}}$ & NG & $<0.01$ \\
\hline Mn, \%TS & $0.01 \pm 0.01$ & $<0.01$ & $0.01 \pm 0.01$ & $<0.01$ & $<0.01$ & $<0.01^{\mathrm{b}}$ & $0.01 \pm 0.01^{\mathrm{b}}$ & $<0.01$ \\
\hline $\mathrm{Fe}, \% \mathrm{TS}$ & $0.07 \pm 0.02$ & $0.08 \pm 0.00$ & $0.09 \pm 0.03$ & $0.06 \pm 0.03$ & $0.06 \pm 0.01$ & $0.08 \pm 0.04^{b}$ & $0.01 \pm 0.00^{\mathrm{b}}$ & $0.01 \pm 0.00$ \\
\hline $\mathrm{Ni}, \% \mathrm{TS}$ & $<0.01$ & $<0.01$ & 0 & $<0.01$ & 0 & $<0.01^{\text {b }}$ & NG & $<0.01$ \\
\hline
\end{tabular}

Table 2. Elemental composition of KW examined in this study and in literature.

* Treatment by high-temperature sterilization pot at $120^{\circ} \mathrm{C}$ for two hours plus removal of lipids, a "O" was calculated based on Eq.: 99.5\%VS $=\mathrm{C}+\mathrm{H}+\mathrm{O}+\mathrm{N},{ }^{\mathrm{b}}$ Based on wet basis, NG: not given 
$\ldots$ where $B$ is the cumulative methane yield ( $\mathrm{mL} / \mathrm{g}-\mathrm{VS}_{\text {added }}$ ), $B_{0}$ is the ultimate methane yield ( $\mathrm{mL} / \mathrm{g}-\mathrm{VS}_{\text {added }}$ ), $\lambda$ refers the lag phase time (d), $\mu_{m}$ stand for maximum methane production rate (mL/g-VS $\left.{ }_{\text {added }} / \mathrm{d}\right), e$ is equal to 2.71821828 , $t$ is the digestion time (d), $k$ is the first-order rate constant $\left(\mathrm{d}^{-1}\right)$, and $n$ is the shape factor (dimensionless).

\section{Results and Discussion}

\section{Characteristics of Substrates}

Characteristics of KW from different sources are shown in Table 2. The VS/TS ratio ranged from $89.8 \%$ to $93.5 \%$ in all KW samples, which is desirable for biomethane production as a higher VS/TS ratio indicates higher organic content [14]. On a total weight basis, KW from the canteen showed the lowest TS and VS contents. The C/N ratios of HP, HC, FF, UC, and Other were 20.6, 19.3 , 26.7, 17.5, and 16.4, respectively, which is suitable for methane production as previous research suggested that a proper $\mathrm{C} / \mathrm{N}$ ratio for $\mathrm{AD}$ ranged from 15.0 to 30.0 [15]. Compared to previous research (Table 2), KW contains relatively high moisture ( $>70 \%)$, high VS/TS ratio (>85\%), and suitable $\mathrm{C} / \mathrm{N}$ ratio (14.8-26.7).

Besides, abundant nutrient elements were detected in all KW samples (Table 2). Among them, elements of P (0.39-0.84\%), K (1.82-2.82\%), Na (2.23-3.49\%), and Ca (2.74-3.94\%) (on TS basis) are essential for microbial growth. Trace metal elements of $\mathrm{Al}, \mathrm{Zn}, \mathrm{Cu}, \mathrm{Mn}$, and Fe were also detected. Metal concentration is a vital parameter in methane formation as bioavailable trace metals could stimulate the conversion of pollutants into methane and improve the tolerance of microorganisms to toxic substances [18-19]. But metal concentrations should not exceed the allowable standards [20-21].

\section{Biomethane Potential}

Biogas production from five different sources of $\mathrm{KW}$ is shown in Fig. 1. After 21 days digestion, HP produced the highest methane yield at $363.9 \pm 38.9 \mathrm{~mL} / \mathrm{g}-\mathrm{VS}_{\text {added }}$ among

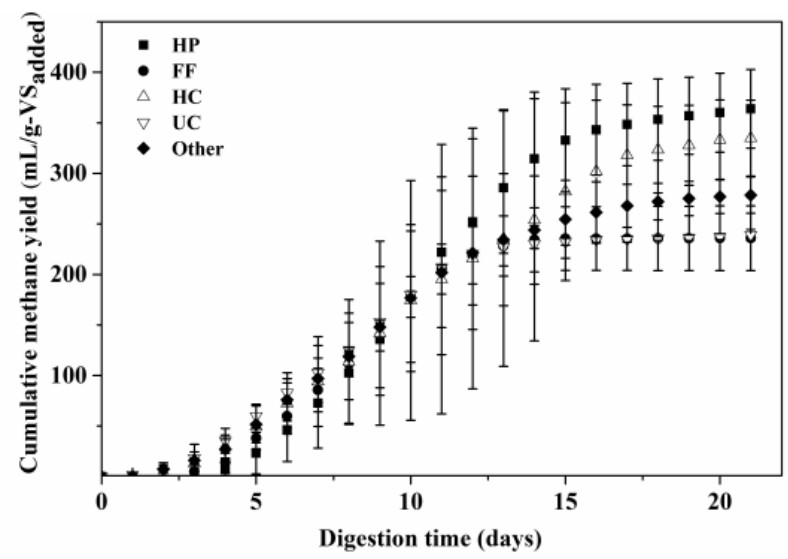

Fig. 1. Cumulative methane yield from various KW samples.

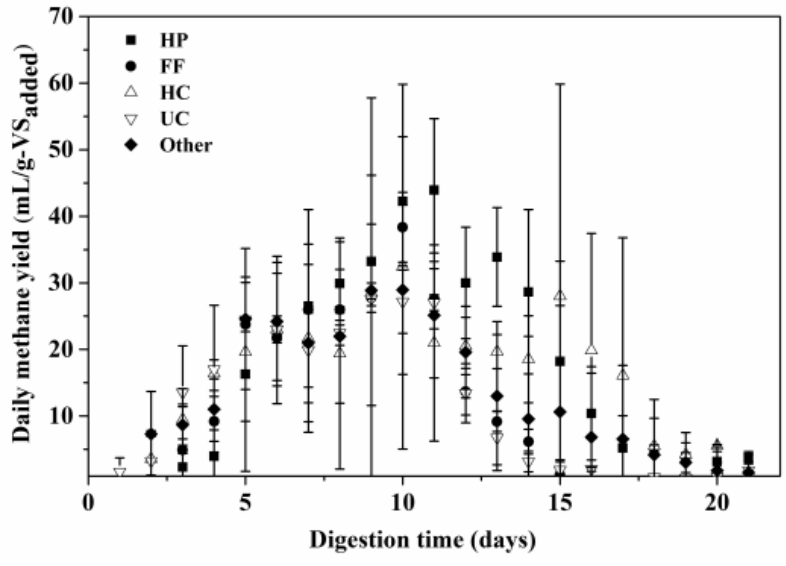

Fig. 2. Daily methane yield from various KW samples.

all the samples, followed by FF (334.8 mL/g-VS ${ }_{\text {added }}$ ), Other (278.5 mL/g-VS $\left.{ }_{\text {added }}\right)$, UC (239.2 $\mathrm{mL} / \mathrm{g}-\mathrm{VS}_{\text {added }}$ ), and HC (236.0 mL/g-VS added $_{\text {aded }}$ ). Large standard deviations were found in BMP tests due to the sampling method, indicating that sample sources significantly influenced the biomethane potential of KW. It is worth noting that HP had the longest lag phase compared to other samples (Figs 1-2). This may be related to the relatively high lipid content of HP (Fig. 3), as previous research demonstrated that the sample with higher lipid content produced more methane with relative extension of the lag phase [22]. The lipid content in KW ranged from $18.6 \%$ to $30.6 \%$. The daily methane generation of HP increased dramatically from day 4 and reached peak production of $43.9 \pm 10.7 \mathrm{~mL} /$ g-VS $_{\text {added }}$ on day 11 (Fig. 2). Daily methane production of $\mathrm{FF}$ and HC increased gradually from day 1 and reached the peak of $32.4 \pm 27.4 \mathrm{~mL} / \mathrm{g}-\mathrm{VS}_{\text {added }}$ and $38.4 \pm 5.2 \mathrm{~mL} / \mathrm{g}-$ $\mathrm{VS}_{\text {added }}$ on day 10, respectively (Fig. 2), which is relatively earlier than HP. According to methane production results, HP had the highest methane production potential.

As can be seen from Fig. 3, theoretical methane yields of different sources of KW ranged from 605.8 $\mathrm{mL} / \mathrm{g}-\mathrm{VS}_{\text {added }}$ to $721.4 \mathrm{~mL} / \mathrm{g}-\mathrm{VS}_{\text {added }}$ by using elemental and organic composition analysis methods [5]. Thus, the biodegradability of KW was found to be 39.5-50.4\%. The methane yields and biodegradability obtained in this study was relatively low as compared to the values reported by Zhang et al. [4], where methane yield was $435 \mathrm{~mL} / \mathrm{g}-\mathrm{VS}_{\text {added }}$ and VS destruction was $81 \%$. It is worth noting that a certain amount of floating brown particles (FBP) formed during the AD process. In this research, further analysis was performed to investigate the physicochemical property of floating brown particles (data is shown in 3.4).

\section{Kinetic Models}

Modified Gompertz and Cone models were used in this study for describing and predicting AD processes [13]. The calculated parameters are shown in Table 3. For the Cone model, the determination coefficient $\left(\mathrm{R}^{2}\right)$ ranged 

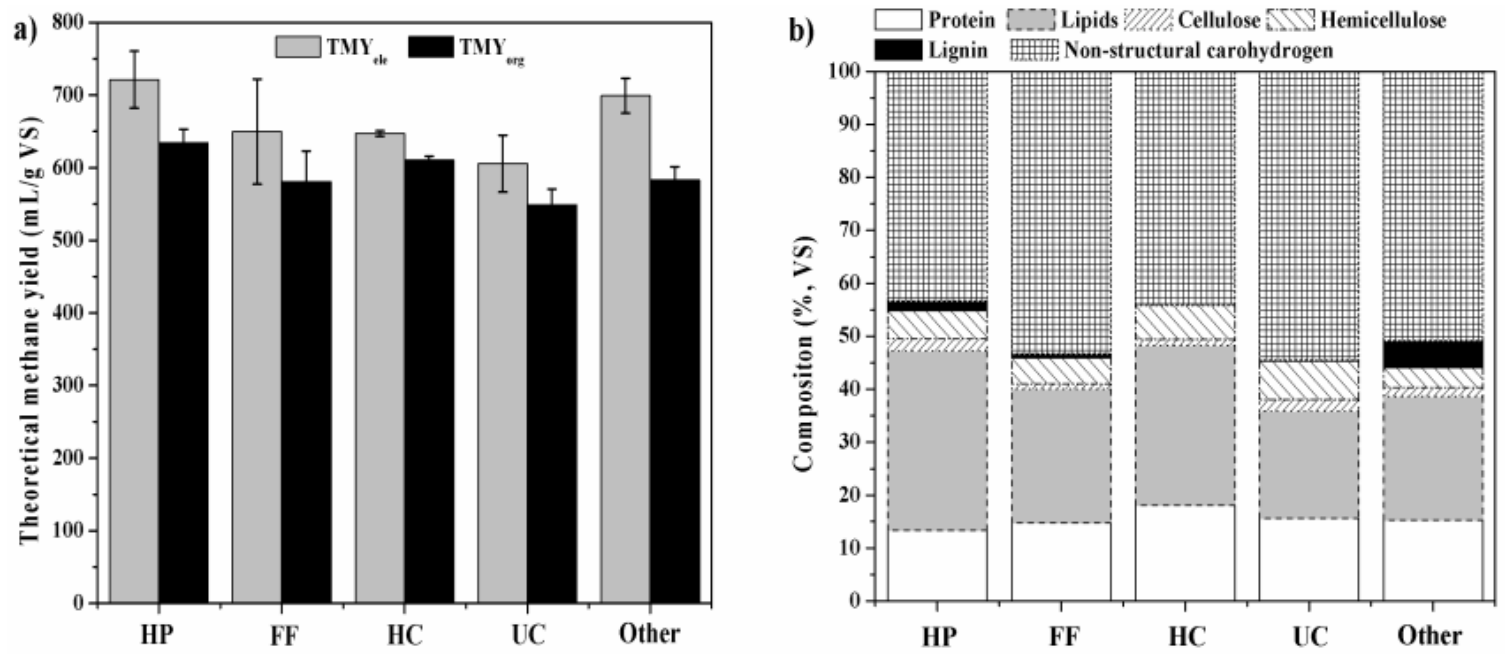

Fig. 3. TMY and composition of KW samples.

from 0.994 to 0.999 . For the modified Gompertz model, $\mathrm{R}^{2}$ ranged from 0.992 to 0.998 . Higher $\mathrm{R}^{2}$ indicated that the assumption of Cone and modified Gompertz models can suit AD tests well. Based on the Cone results, the hydrolysis rate constants $(k)$ for HP, HC, FF, UC, and Other were $0.098,0.124,0.099,0.132$, and $0.112 \mathrm{~d}^{-1}$, respectively, which were comparable with values of $0.050-0.240 \mathrm{~d}^{-1}$ and $0.127-0.193 \mathrm{~d}^{-1}$ as reported by Li et al. [5] and Qiao et al. [23]. According to the results of modified Gompertz, KW from HP showed the highest lag phase time $(\lambda)$ of $5.46 \mathrm{~d}$, which indicates the longest startup occurring in the HP digester. It is worth noting that HP contains the highest content of lipids (30.9\% of TS, Fig. 3), while the degradation rate of lipids is slow for microorganisms. Maximum methane production rate $\left(\mu_{m}\right)$ and ultimate methane yield $\left(B_{0}\right)$ were found in HP, which may also be due to the contribution of lipids.

\section{Analysis of Floating Brown Particles}

\section{SEM and Energy Spectrum Analysis}

The scanning electron micrograph (SEM) showed that the floating brown particles have multi-layer structure (Fig. 4), which may form superimposed "particles."
As shown in Fig. 5, During AD, FBP were found at the centimeter level. Energy spectrum analysis showed that the floating brown particles mainly contained three elements: $\mathrm{C}, \mathrm{O}$, and $\mathrm{Ca}$. The mass fractions of $\mathrm{C}, \mathrm{O}$, and Ca in the brown particles are $67.49 \%, 26.78 \%$, and $4.28 \%$, respectively, and the atomic numbers are $75.40 \%, 22.46 \%$, and $1.43 \%$, respectively. The analysis revealed organic matter composition of the floating brown particles.

\section{${ }^{13}$ C NMR and FTIR Analysis}

${ }^{13} \mathrm{C}$ NMR profiles of the samples indicated that the floating brown particle sample has different contents of C-containing groups (Fig. 6). According to resonance signals in ${ }^{13} \mathrm{C}$ NMR spectra and attributed chemicals, groups appearing in the region of $0-50 \mathrm{ppm}$ are either groups of methylene $\left(-\mathrm{CH}_{2}\right)$ or methyl $\left(-\mathrm{CH}_{3}\right)$; the peak at $179.30 \times 10^{-6}$ is carboxylic acid radical anion group (-COO). Based on analysis results of ${ }^{13} \mathrm{C}$ NMR and FTIR, the sample is mainly composed of three groups: methy-lene $\left(-\mathrm{CH}_{2}\right)$, methyl $\left(-\mathrm{CH}_{3}\right)$, and carboxylate anion

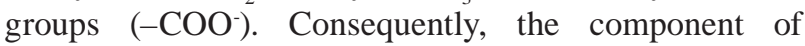
the sample can be inferred as carboxylic acid salts of saturated chain structure $\left[\mathrm{CH}_{3}\left(-\mathrm{CH}_{2}-\right)_{n} \mathrm{COO}^{-}\right]$. An FTIR spectrogram showed that the number of methylene was

Table 3. Parameters of Cone and modified Gompertz models for different types of KW.

\begin{tabular}{|c|c|c|c|c|c|c|c|c|}
\hline \multirow[b]{2}{*}{ Substrates } & \multicolumn{4}{|c|}{ Cone model } & \multicolumn{4}{|c|}{ Modified Gompertz model } \\
\hline & $\begin{array}{c}B_{0} \\
\left(\mathrm{~mL}^{-\mathrm{CH}_{4}} / \mathrm{g}-\right. \\
\left.\mathrm{VS}_{\text {added }}\right)\end{array}$ & $k\left(\mathrm{~d}^{-1}\right)$ & $n$ & $\mathrm{R}^{2}$ & $\begin{array}{c}B_{0} \\
\left(\mathrm{~mL}_{0}-\mathrm{CH}_{4} / \mathrm{g}-\right. \\
\left.\mathrm{VS}_{\text {added }}\right)\end{array}$ & $\begin{array}{c}\mu_{m} \\
(\mathrm{~mL} / \mathrm{g}- \\
\left.\mathrm{VS}_{\text {added }} / \mathrm{d}\right)\end{array}$ & $\lambda(\mathrm{d})$ & $\mathrm{R}^{2}$ \\
\hline $\mathrm{HP}$ & $387.2 \pm 4.8$ & $0.098 \pm 0.001$ & $4.20 \pm 0.14$ & 0.999 & $380.0 \pm 4.2$ & $41.1 \pm 1.1$ & $5.46 \pm 0.12$ & 0.998 \\
\hline $\mathrm{HC}$ & $245.9 \pm 3.6$ & $0.124 \pm 0.002$ & $4.43 \pm 0.27$ & 0.995 & $243.0 \pm 3.0$ & $34.3 \pm 1.7$ & $4.41 \pm 0.18$ & 0.995 \\
\hline $\mathrm{FF}$ & $360.9 \pm 2.0$ & $0.099 \pm 0.001$ & $3.15 \pm 0.12$ & 0.994 & $376.0 \pm 6.4$ & $27.0 \pm 0.6$ & $3.68 \pm 0.14$ & 0.998 \\
\hline UC & $253.1 \pm 5.2$ & $0.132 \pm 0.003$ & $3.31 \pm 0.22$ & 0.994 & $245.1 \pm 3.1$ & $29.0 \pm 1.3$ & $3.18 \pm 0.19$ & 0.995 \\
\hline Other & $305.5 \pm 4.5$ & $0.112 \pm 0.002$ & $2.98 \pm 0.10$ & 0.998 & $289.1 \pm 2.2$ & $27.8 \pm 0.5$ & $3.43 \pm 0.09$ & 0.992 \\
\hline
\end{tabular}



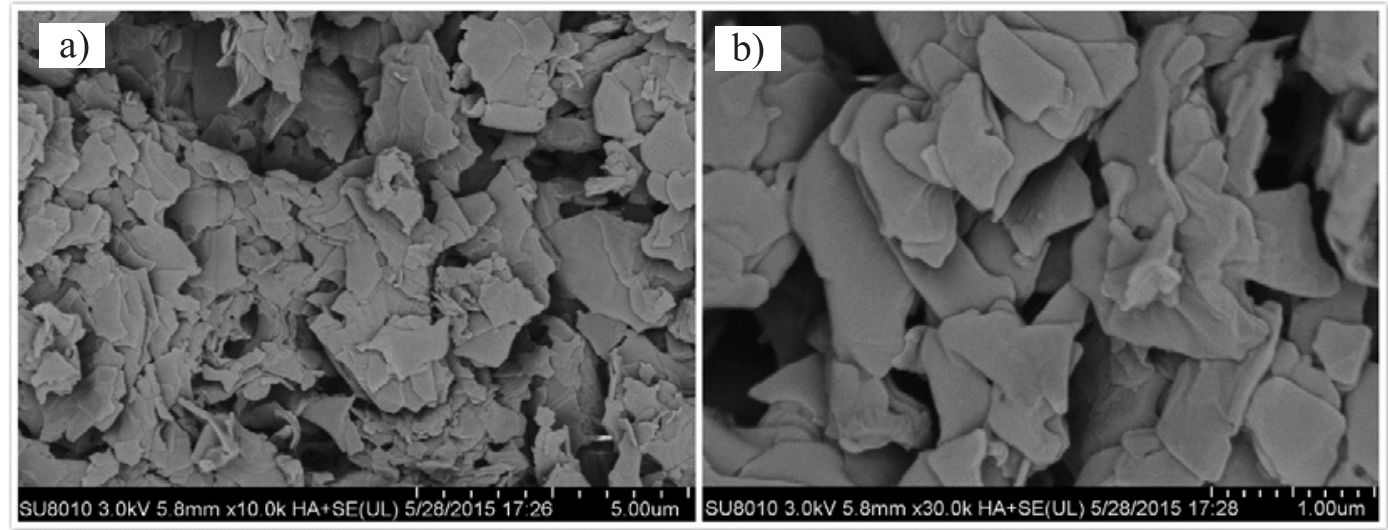

Fig. 4. Scanning electron micrograph of brown particle powder: a) test at $30 \mathrm{kV}, 5.8 \mathrm{~mm} \times 10.0 \mathrm{k}$; b) test at $30 \mathrm{kV}, 5.8 \mathrm{~mm} \times 30.0 \mathrm{k}$.

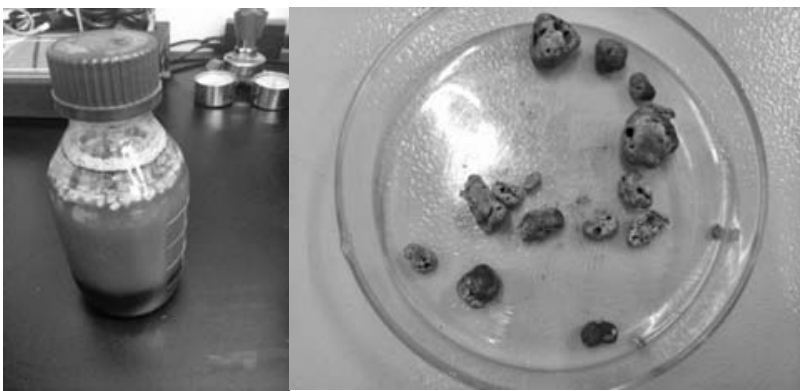

Fig. 5. Brown particles formed during AD.

16 [24]. As "Ca" was the main element $(2.74-3.94 \%$ on TS basis) in the floating brown particle, the component of the sample was likely to be calcium stearate. FTIR spectroscopy comparison further confirmed the similarity composition of floating brown particles and calcium stearate (Fig. 7). Although the absorption of the brown particles and the calcium stearate is slightly different, the peak position is basically the same.

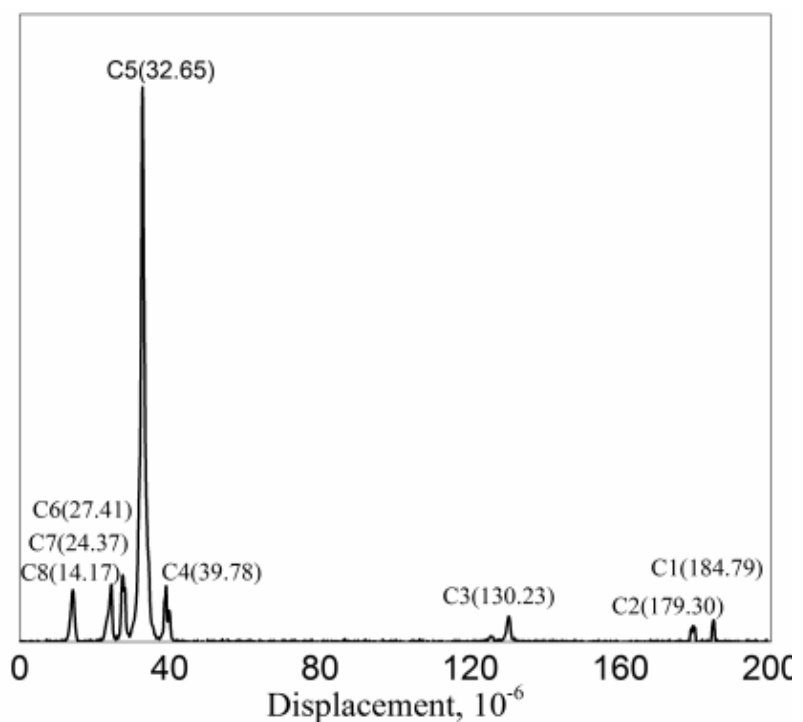

Fig. $6 .{ }^{13} \mathrm{C}$ NMR profiles of the KW samples.
Lipids were hydrolyzed by extracellular lipase generating glycerol and LCFAs (such as hexadecanoic acid and stearic acid). During the hydrolyzing process, parts of the saturated fatty acid reacted with $\mathrm{Ca}^{2+}$ and formed calcium stearate [25]. The accumulation of calcium stearate resulted in agglomeration and formed floating granules. This reaction leads to a decrease in the accumulation of LCFAs, which subsequently reduced the inhibition effect on AD reaction and methane production. For AD of lipid-rich substrates, to reduce the inhibition of LCFAs, $\mathrm{Ca}^{2+}$ can be added into the digester. However, the decrease of intermediates (LCFAs) on the other hand also results in insufficient bioavailable nutrients, which restrict methane production.

\section{Conclusions}

The present study investigated the potential of biogas and methane generation from different sources of KW collected from China. Results indicated that methane production vary with different sources of KW. Compared to FF, HC UC, and other sources of KW,

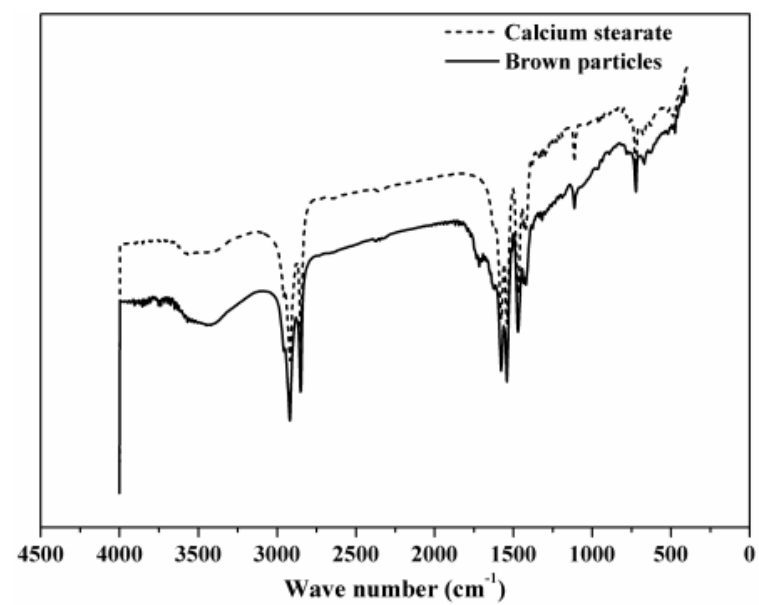

Fig. 7. FTIR spectroscopy of floating brown particles and calcium stearate. 
HP showed the highest methane production potential of $363.9 \pm 38.9 \mathrm{~mL} / \mathrm{g}-\mathrm{VS}_{\text {added }}$, which may be due to its relatively high lipid content. During anaerobic digestion, a certain amount of floating brown particles (FBP) were observed. Combined with energy spectrum, SEM, ${ }^{13} \mathrm{C}$ NMR, and FTIR analysis, it can be inferred that the brown particles are likely to be calcium stearate. The formation mechanism of calcium stearate may contribute to the reaction between accumulated LCFAs and $\mathrm{Ca}^{2+}$. The formation of the particles on the one hand reduced the toxicity of LCFA accumulation, whereas on the other side it may play a role in the inhibition of biogas output. Based on the results, when using lipid-rich substrates as feedstock, it may be an efficient approach to add $\mathrm{Ca}^{2+}$ artificially to reduce the inhibition of LCFAs. Meanwhile, the biodegradability of floating brown particles needs to be further investigated.

\section{Acknowledgements}

This work was supported by the Beijing Municipal Science and Technology Project (No. D141100002814001), the Science Foundation of China University of Petroleum, Beijing (Nos. 2462014YJRC034 and C201604), and the Co-Construction Project of the Beijing Municipal Education Commission. We are grateful to the anonymous reviewers and editors for their valuable suggestions and comments on revising and improving this work.

\section{References}

1. ZHANG C., SU H., BAEYENS J., TAN T. Reviewing the anaerobic digestion of food waste for biogas production. Renew. Sust. Energ. Rev. 38, 383, 2014.

2. LIU G., LIU X., LI Y., HE Y., ZHANG R. Influence of pH adjustment and inoculum on anaerobic digestion of kitchen waste for biogas producing. J. Biobased Mater. Bio. 5 (3), 390, 2011.

3. GIROTTO F., ALIBARDI L., COSSU R. Food waste generation and industrial uses: A review. Waste Manage. 45, 32, 2015.

4. ZHANG R., EL-MASHAD H.M., HARTMAN K., WANG F., LIU G., CHOATE C., GAMBLE P. Characterization of food waste as feedstock for anaerobic digestion. Bioresour. Technol. 98 (4), 929, 2017.

5. LI Y., ZHANG R., LIU G., CHEN C., HE Y., LIU $\mathrm{X}$. Comparison of methane production potential, biodegradability, and kinetics of different organic substrates. Bioresour. Technol. 149, 565, 2013.

6. PEREIRA M.A., SOUSA D.Z., MOTA M., ALVES M.M. Mineralization of LCFA associated with anaerobic sludge: kinetics, enhancement of methanogenic activity, and effect of VFA. Biotechnol. Bioeng. 88 (4), 502, 2014.

7. CIRNE D.G., PALOUMET X., BJORNSSON L., ALVES M.M., MATTIASSON B. Anaerobic digestion of lipid-rich waste-effects of lipid concentration. Renew. Energ. 32 (6), 965, 2017.

8. WAGNER U., MAURER M., RUCKERT C. Abschlussbericht zum Vorhaben Biogasanlage Flugplatz Köthen: Vergärung von Hühnertrockenkot Gut Mennewitz GmbH. 2010.
9. NIE H., JACOBI H.F., STRACH K., XU C., ZHOU H., LIEBETRAU J. Mono-fermentation of chicken manure: Ammonia inhibition and recirculation of the digestate. Bioresour. Technol. 178, 238, 2015.

10. TANAKA S., KOBAYASHI T., KAMIYAMA K.I., BILDAN M. Effects of thermochemical pretreatment on the anaerobic digestion of waste activated sludge. Water Sci. Technol. 35 (8), 209, 1997.

11. LI Y., LIU H., SU D.F., YAN F. Characterization and thermophilic anaerobic digestion of organic fraction of municipal solid waste. Waste Biomass Valor. 7, 325, 2016.

12. APHA. Standard Methods for the Examination of Water and Wastewater, $18^{\text {th }}$ ed American Public Health Association, DC, USA, 1998.

13. LI Y., ZHANG R., HE Y., LIU X., CHEN C., LIU G. Thermophilic solid-state anaerobic digestion of alkalinepretreated corn stover. Energ. Fuel. 28 (6), 3759, 2014.

14. NELSON R. Methane generation from anaerobic digesters: considering different substrates Environmental Biotechnology,-Iowa State University, USA, 2010.

15. LI Y., ZHANG R., CHEN C., LIU G., HE Y., LIU X. Biogas production from co-digestion of corn stover and chicken manure under anaerobic wet, hemi-solid, and solid state conditions. Bioresour. Technol. 149, 406, 2013.

16. ZHANG C., SU H., TAN T. Batch and semi-continuous anaerobic digestion of food waste in a dual solid-liquid system. Bioresour. Technol. 145, 10, 2013.

17. ZHANG C., SU H., WANG Z., TAN T., QIN P. Biogas by semi-continuous anaerobic digestion of food waste. Appl. Biochem. biotech. 175 (8), 3901, 2015.

18. YIRONG C., HEAVEN S., BANKS C.J. Effect of a trace element addition strategy on volatile fatty acid accumulation in thermophilic anaerobic digestion of food waste. Waste Biomass Valor. 6 (1), 1, 2015.

19. ZHANGW.,ZHANGL., LIA.Enhanced anaerobic digestion of food waste by trace metal elements supplementation and reduced metals dosage by green chelating agent $[\mathrm{S}, \mathrm{S}]-$ EDDS via improving metals bioavailability. Water Res. 84, 266, 2015.

20. ZHU B., GIKAS P., ZHANG R., LO J., JENKINS B., LI X. Characteristics and biogas production potential of municipal solid wastes pretreated with a rotary drum reactor. Bioresour Technol 100 (3), 1122, 2009.

21. BOZYM M., FLORCZAK I., ZDANOWSKA P., WOJDALSKI J., KLIMKIEWICZ M. An analysis of metal concentrations in food wastes for biogas production. Renew. Energ. 77, 467, 2015.

22. MENG Y., LI S., YUAN H., ZOU D., LIU Y., ZHU B., LI X. Evaluating biomethane production from anaerobic mono-and co-digestion of food waste and floatable oil (FO) skimmed from food waste. Bioresour. Technol. 185, 7, 2015.

23. QIAO W., MOHAMMAD S., TAKAYANAGI K., LI Y.Y. Thermophilic anaerobic co-digestion of coffee grounds and excess sludge: long term process stability and energy production. RSC Adv. 5 (34), 26452, 2015.

24. LIU Y., CHEN X., ZHU B., YUAN H., ZHOU Q., XIA Y., LI X. Formation and function of calcium stearate in anaerobic digestion of food waste. Chinese J. Environ. Eng. 5, 2844, 2011.

25. PITK P., PALATSI J., KAPARAJU P., FERNANDEZ B., VILU R. Mesophilic co-digestion of dairy manure and lipid rich solid slaughterhouse wastes: Process efficiency, limitations and floating granules formation. Bioresour. Technol. 166, 168, 2014. 